Part of Journal of Research of the National Bureau of Standards, Volume 19, September 1937

\title{
HEATS OF COMBUSTION AND OF FORMATION OF THE NORMAL OLEFIN (ALKENE-1) HYDROCARBONS IN THE GASEOUS STATE
}

\author{
By Frederick D. Rossini and John W. Knowlton
}

\section{ABSTRACT}

The existing thermochemical data on the normal olefin (alkene-1) hydrocarbons are reviewed and correlated. These data are used in conjunction with the value previously proposed for the increase in the heat content per added $\mathrm{CH}_{2}$ group to obtain values for those members of this series of hydrocarbons for which no calorimetric data exist. For all these hydrocarbons in the gaseous state, selected "best" values are given for the heats of combustion at $25^{\circ} \mathrm{C}$ and for the heats of formation, from solid carbon and gaseous hydrogen, at $25^{\circ} \mathrm{C}$ and $0^{\circ} \mathrm{K}$.

As in the case of the previously reported values for the normal paraffin hydrocarbons and primary normal alkyl alcohols, the heats of formation of the gaseous normal olefin (alkene-1) hydrocarbons can be represented by means of an expression of the form $\Delta H=A+B n+\Delta$, where $\Delta H$ is the heat of formation, $A$ and $B$ are constant for a given temperature, $n$ is the number of carbon atoms in the molecule $\mathrm{C}_{n} H_{2 n}$, and $\Delta$ is the term giving the deviation from linearity, which is zero for $n>5$. Values of the constants $A$ and $B$ and of $\Delta$ are given both for $25^{\circ} \mathrm{C}$ and $0^{\circ} \mathrm{K}$.

\section{CONTENTS}

I. Introduction _...

II. Units of energy and molecular weights

III. Existing data

IV. Selected "best" values for the heats of combustion at $25^{\circ}$ C_...... 341

V. Heats of formation at $25^{\circ} \mathrm{C}$ and $0^{\circ} \mathrm{K} \ldots$

VI. References

\section{INTRODUCTION}

The purpose of the present paper is to deduce reliable values for the heats of combustion and of formation of all the normal olefin (alkene-1) hydrocarbons in the gaseous state by using the following:

(1) the generalization recently made by one of the authors [1] ${ }^{1}$ that, in any organic molecule containing a normal alkyl group of more than five carbon atoms, the addition of a $\mathrm{CH}_{2}$ group to the normal alkyl radical to form the next higher normal alkyl group results in an increase in the heat of combustion of the organic molecule in the gaseous state, at a temperature of $25^{\circ} \mathrm{C}$ and a constant total pressure of 1 atmosphere, of $157.00 \pm 0.08$ kilocalories per mole; (2) the heats of combustion of ethylene and propylene recently measured in this laboratory [2]; (3) the heats of hydrogenation of ethylene, propylene, normal butene-1, and normal heptene-1 recently reported by Kistiakowsky, Vaughan, et al. [3, 4]; and (4) the heats of combustion of hydrogen and of the gaseous normal paraffin hydrocarbons as reported from this laboratory $[5,1]$.

\footnotetext{
1 The numbers in brackets here and throughout the text refer to the references at the end of the paper.
} 


\section{UNITS OF ENERGY AND MOLECULAR WEIGHTS}

The values of energy given in this paper are based upon the international joule as derived from standards maintained at this Bureau. As in previous papers, the following conversion factor [6] is used for reporting the results in terms of the defined calorie:

\section{NBS international joule $=1 / 4.1833$ calorie.}

The establishment of the uncertainties attached to the various values presented in this paper follows the procedure described in reference [6].

It is to be emphasized that the molal units of mass associated with the values given for the heats of combustion represent true moles well within the limits of uncertainty of the selected values because (1) the experimental values of heats of combustion are entirely independent of the atomic weight of carbon, the number of moles of hydrocarbon being determined from the mass of $\mathrm{H}_{2} \mathrm{O}$ formed in the combustion [1, 8], and (2) the relatively small values of heats of hydrogenation are expressed in terms of moles as determined from the mass of $\mathrm{CO}_{2}$, so that in this latter case the atomic weight of carbon enters as only $12 / 44$ and can make only a negligible absolute error in the energy value finally deduced. For the heats of formation, a little greater uncertainty [1] is introduced because the existing data for the heat of formation of carbon dioxide from its elements are based upon the mass of carbon burned, and consequently the values carry the full uncertainty in the value for the atomic weight of carbon, in addition to the calorimetric and thermodynamic uncertainties.

\section{EXISTING DATA}

The existing data on the heats of combustion of ethylene and propylene have already been reviewed $[2,7]$.

"Calculated" values for the heats of combustion of ethylene and propylene have also been derived by the authors [2] using values for the heats of combustion of hydrogen, ethane, and propane obtained in this laboratory $[5,8]$ and values for the heats of hydrogenation of ethylene and propylene obtained at Harvard University [3, 4]:

$$
\begin{gathered}
\mathrm{C}_{n} \mathrm{H}_{2 n+2}(\mathrm{~g})+\frac{3 n+1}{2} \mathrm{O}_{2}(\mathrm{~g})=n \mathrm{CO}_{2}(\mathrm{~g})+(n+1) \mathrm{H}_{2} \mathrm{O}(\mathrm{liq}) \\
(n+1) \mathrm{H}_{2}(\mathrm{~g})+\frac{n+1}{2} \mathrm{O}_{2}(\mathrm{~g})=(\mathrm{n}+1) \mathrm{H}_{2} \mathrm{O}(\text { liq }) \\
\mathrm{C}_{n} \mathrm{H}_{2 n}(\mathrm{~g})+\mathrm{H}_{2}(\mathrm{~g})=\mathrm{C}_{n} \mathrm{H}_{2 n+2}(\mathrm{~g})
\end{gathered}
$$

The sum of reactions (1) and (3), less reaction (2), yields the reaction for the combustion of the olefin hydrocarbon:

$$
\mathrm{C}_{n} \mathrm{H}_{2 n}(\mathrm{~g})+3 n \mathrm{O}_{2}(\mathrm{~g})=n \mathrm{CO}_{2}(\mathrm{~g})+n \mathrm{H}_{2} \mathrm{O} \text { (liq) }
$$

In a manner similar to that above, there can be obtained "calculated" values for the heats of combustion of gaseous normal butene-1 and gaseous normal heptene-1, using the following data: for the heats of combustion of normal butane and normal heptane, according to reaction (1), $-\Delta H=2877.88 \pm 0.63$ and $4850.12 \pm 2.34$ inter- 
national kilojoules, or $687.94 \pm 0.15$ and $1159.40 \pm 0.56$ kilocalories per mole, respectively, at $25^{\circ} \mathrm{C}$ and 1 atmosphere $[8,1]$; for the heat of formation of liquid water, according to reaction (2), $-\Delta H=285$. $775 \pm 0.040$ international kilojoules, or $68.313 \pm 0.010$ kilocalories per mole at $25^{\circ} \mathrm{C}$ and 1 atmosphere [5]; and for the heats of hydrogenation of normal butene- 1 and normal heptene-1, according to reaction (3), $-\Delta H=125.62 \pm 0.32$ and $124.75 \pm 0.32$ international kilojoules or $30.03 \pm 0.08$ and $29.82 \pm 0.08$ kilocalories per mole at $25^{\circ} \mathrm{C}$ and 1 atmosphere. These Jatter values are derived from the experimentally determined ones for $82^{\circ} \mathrm{C}$ [4] by using for reaction (3) the relation

$\Delta H_{355}-\Delta H_{298}=-0.321 \pm 0.040$ kilocalories per mole which has been calculated by Kassel [17, 18].

From the value thus calculated for the heat of combustion of gaseous normal heptene-1, which should be a reliable one judging from the accord previously found between the "calculated" and experimental values for ethylene and propylene [2], there can be derived values for the heats of combustion of all the normal olefin (alkene-1) hydrocarbons above heptene by using the generalization mentioned in the introduction of this paper [1]. In this manner, there is obtained for the reaction

$$
\mathrm{C}_{n} \mathrm{H}_{2 n}(\mathrm{~g})+\frac{3 n}{2} \mathrm{O}_{2}(\mathrm{~g})=n \mathrm{CO}_{2}(\mathrm{~g})+n \mathrm{H}_{2} \mathrm{O}(\mathrm{liq})
$$

with $n>5$, for $25^{\circ} \mathrm{C}$ and 1 atmosphere,

$$
-\Delta H=178.90+157.00(n-1) \text { kilocalories per mole }
$$

with an uncertainty of about $\pm(0.10 n-0.10)$ kilocalories per mole, where $n$ is the number of carbon atoms per molecule.

There is reported in the literature one value for the heat of combustion of "amylene" and one for "hexylene", the latter being carried out in a bomb at constant volume. The former was reported by Favre and Silbermann [9] in 1852 and the latter by Zubow [10, 11] in 1898. Because of the uncertainty as to the purity and isomeric form of the actual material burned and as to the unit of energy of these early experiments, these two values are considered to be of historical interest only.

The experimental values for ethylene and propylene, and the "calculated" values for ethylene, propylene, normal butene-1, normal heptene-1, and the normal olefins (alkene-1) above heptene, are shown in figure 1. By interpolation on this chart, reliable values are obtained for normal pentene-1 and normal hexene-1, of which neither the heat of combustion nor of hydrogenation has ever been measured experimentally.

\section{SELECTED "BEST" VALUES FOR THE HEATS OF COM- BUSTION AT $25^{\circ} \mathrm{C}$}

From the values given by the curve in figure 1, the selected "best" values given in table 1 are obtained for the heats of combustion of all the normal olefin (alkene-1) hydrocarbons in the gaseous state at $25^{\circ} \mathrm{C}$ and 1 atmosphere, according to reaction (4). For $n>5$, the 
following linear relation (see page 341) holds for reaction (6) at $25^{\circ} \mathrm{C}$ and 1 atmosphere:

$-\Delta H=21.90+157.00 n \pm(0.10 n-0.10)$ kilocalories per mole

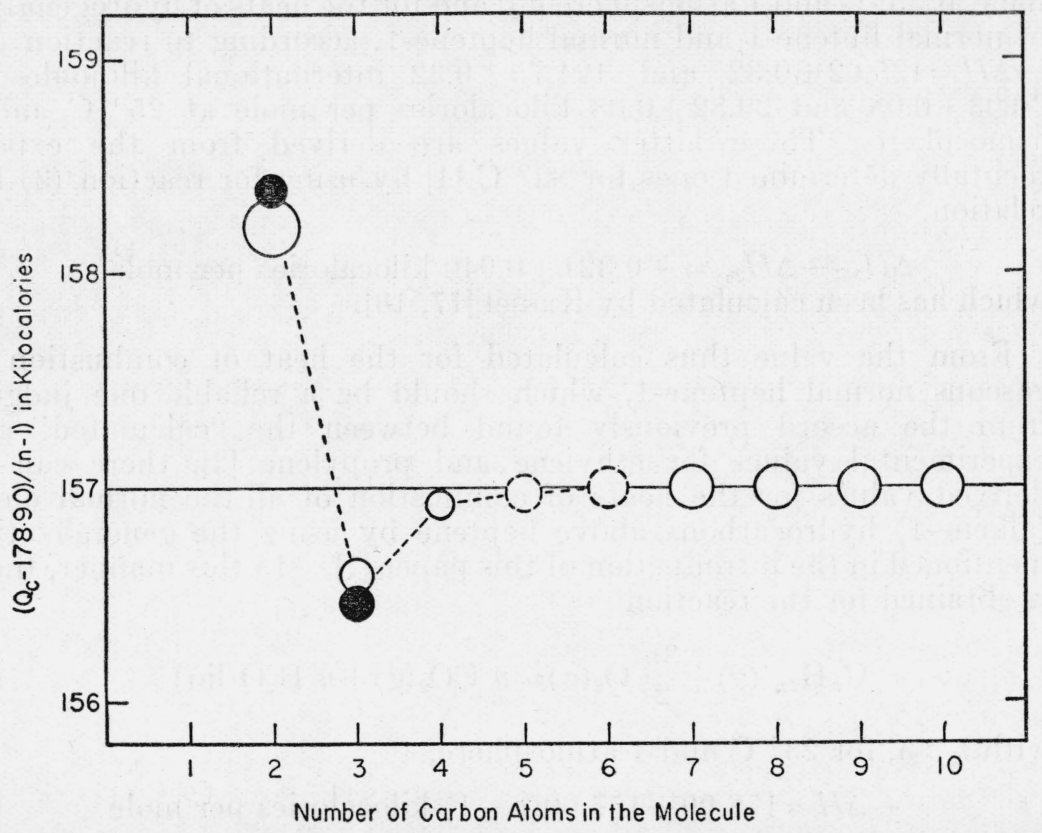

Figure 1.-Relation between the heats of combustion of the gaseous normal olefin

(alkene-1) hydrocarbons and the number of carbon atoms in the molecule.

The scale of ordinates gives the function $(Q c-178.90) /(n-1)$, where $Q c$ is the heat of combustion of the gaseous olefin at $25^{\circ} \mathrm{C}$ and a constant total pressure of 1 atmosphere, in kilocalories per mole, and $n$ is the number of carbon atoms in the molecule. The scale of abscissas gives the number of carbon atoms in the molecule. The solid black circles represent directly measured values [2]; the open circles represent calculated values (see p. 341); the broken circles represent interpolated values. The radii of the various circles represent the estimated uncertainties.

TABLE 1.-Selected "best" values for the heats of combustion of the gaseous normal olefin (alkene-1) hydrocarbons at $25^{\circ} \mathrm{C}$

$$
\mathrm{C}_{n} \mathrm{H}_{2 n}(\mathrm{~g})+\frac{3 n}{2} \mathrm{O}_{2}(\mathrm{~g})=n \mathrm{CO}_{2}(\mathrm{~g})+n \mathrm{H}_{2} \mathrm{O}(\mathrm{liq})
$$

\begin{tabular}{|c|c|}
\hline $\mathrm{C}_{n} \mathrm{H}_{2 n}$ (gas) & $-\Delta H$ at $25^{\circ} \mathrm{C}$ and $1 \mathrm{~atm}$ \\
\hline $\begin{array}{l}\text { Ethylene } \\
\text { Propylene } \\
\text { Normal butene-1 } \\
\text { Normal pentene-1 } \\
\text { Normal hexene-1 } \\
\text { Normal heptene-1 } \\
\text { Normal octene-1 } \\
\text { Normal nonene-1 decene-1 } \\
\text { Normal } \mathrm{C}_{n} \mathrm{H}_{2 n}(\text { for } n>5)\end{array}$ & $\begin{array}{l}\text { Kilocalories per mole } 1 \\
337.25 \pm 0.07 . \\
491.90 \pm 0.15 \\
649.66 \pm 0.18 \\
806.78 \pm 0.32 \\
963.90 \pm 0.45 \\
1,120.90 \pm 0.60 \\
1,277.90 \pm 0.70 \\
1,434.90 \pm 0.80 \\
1,591.90 \pm 0.90 \\
21.90+157.00 n \pm(0.10 n-0.10)\end{array}$ \\
\hline
\end{tabular}

1 See p. 340 for unit of energy and molecular weights.

\section{HEATS OF FORMATION AT $25^{\circ} \mathrm{C}$ AND $0^{\circ} \mathrm{K}$}

By combining the reaction of combustion as given by equation 4 with the heats of formation of water and of carbon dioxide from their elements, there is obtained the reaction of forming the hydrocarbon 
from its elements. The value for the heat of formation of water according to reaction (2) has already been given. For the heat of formation of carbon dioxide from its elements,

$$
\begin{aligned}
\mathrm{C} \text { (c, graphite })+\mathrm{O}_{2}(\mathrm{~g}) & =\mathrm{CO}_{2}(\mathrm{~g}), \\
\mathrm{C}(\mathrm{c} \text {, diamond })+\mathrm{O}_{2}(\mathrm{~g}) & =\mathrm{CO}_{2}(\mathrm{~g}),
\end{aligned}
$$

a previous review of the existing data [1] yielded, for reaction (9), $-\Delta H=94.20 \pm 0.08$ kilocalories per mole at $25^{\circ} \mathrm{C}$ and 1 atmosphere, where the amount of reaction was determined from the mass of carbon and 1 gram-atom of carbon was taken as $12.007 \pm 0.003 \mathrm{~g}$. The International Committee on Atomic Weights this year [16] changed the value for the atomic weight of carbon from 12.00 to 12.01 . The available data indicate rather definitely that the uncertainty in the new value cannot be more than about 0.003 . Taking 1 mole of carbon dioxide as given by $12.010 \pm 0.003 \mathrm{~g}$ of carbon, the value for the heat of reaction (9) becomes $-\Delta H=94.22 \pm 0.08$ kilocalories per mole at $25^{\circ} \mathrm{C}$ and 1 atmosphere. Since this value is still substantially the same as the old one, 94.24 (see [1]), the values already used [1] for reactions (9) and (10), namely, $-\Delta H=94.24 \pm 0.10$ and $94.46 \pm 0.10$ kilocalories per mole, respectively, at $25^{\circ} \mathrm{C}$ and 1 atmosphere, will be used in the present calculations.

With the foregoing values for the heats of formation of water and carbon dioxide and the values for the heats of combustion given in table 1 , there are obtained the values for the heats of formation of the gaseous normal olefin (alkene-1) hydrocarbons at $25^{\circ} \mathrm{C}$ as given in table 2 .

For the reaction

$$
n \mathrm{C}(\mathrm{c}, \text { graphite })+n \mathrm{H}_{2}(\mathrm{~g})=\mathrm{C}_{n} \mathrm{H}_{2 n}(\mathrm{~g})
$$

$\Delta H^{\circ}{ }_{298.16}=21.90-5.55_{3} n+\Delta \pm(0.14 n-0.06)$, kilocalories per mole,

where $\Delta=0$ for $n>5$, and has the following values for $n \leqslant 5$ : ethylene, $1.35 \pm 0.07$; propylene, $-1.00 \pm 0.15$; normal butene- $1,-0.24 \pm 0.18$; normal pentene- $1,-0.12 \pm 0.32$, kilocalories per mole.

For the reaction

$$
n \mathrm{C} \text { (c, diamond) }+n \mathrm{H}_{2}(\mathrm{~g})=\mathrm{C}_{n} \mathrm{H}_{2 n}(\mathrm{~g})
$$

$\Delta H^{\circ}{ }_{298.16}=21.90-5.77_{3} n+\Delta \pm(0.14 n-0.06)$ kilocalories per mole, $(14)$

\begin{tabular}{|c|c|c|c|c|}
\hline \multirow{2}{*}{$\mathrm{C}_{n} \mathrm{H}_{2 n}(\mathrm{~g})$} & \multicolumn{2}{|c|}{$n \mathrm{C}(\mathrm{c}$, graphite $)+n \mathrm{H}_{2}(\mathrm{~g})=\mathrm{C}_{n} \mathrm{H}_{2 n}(\mathrm{~g})$} & \multicolumn{2}{|c|}{$n \mathrm{C}(\mathrm{c}$, diamond $)+n \mathrm{H}_{2}(\mathrm{~g})=\mathrm{C}_{n} \mathrm{H}_{2 n}(\mathrm{~g})$} \\
\hline & $\Delta H_{288.16}^{\circ}$ & $\Delta H_{0}^{\circ}$ & $\Delta H_{288.16}^{\circ}$ & $\Delta H_{0}^{\circ}$ \\
\hline Ethylene & $\begin{array}{r}\text { Kilocalories } \\
12.1 \\
4.2 \\
-0.5 \\
-5.9 \\
-11.4\end{array}$ & \begin{tabular}{|r|} 
Kilocalories per Mole \\
$14.16 \pm 0.21$ \\
$7.61 \pm 0.35$ \\
$4.33 \pm 0.46$ \\
$0.42 \pm 0.63$ \\
$-3.49 \pm 0.79$
\end{tabular} & \begin{tabular}{|r|} 
Kilocalories per Mole \\
$11.70 \pm 0.21$ \\
$3.58 \pm 0.34$ \\
$-1.43 \pm 0.44$ \\
$-7.09 \pm 0.60$ \\
$-12.74 \pm 0.76$
\end{tabular} & $\begin{array}{r}\text { Kilocalories per Mole } \\
13.47 \pm 0.21 \\
6.57 \pm 0.35 \\
2.95 \pm 0.46 \\
-1.31 \pm 0.63 \\
-5.57 \pm 0.79\end{array}$ \\
\hline $\begin{array}{l}\text { Normal heptene-1... } \\
\text { Normal octene-1.-. } \\
\text { Normal nonene-1.... } \\
\text { Normal decene-1.... } \\
\begin{array}{l}\text { Normal } \mathrm{C}_{n} \mathrm{H}_{2 n} \\
n>5 \text { (for }\end{array}\end{array}$ & $\begin{array}{r}-16.97 \pm 0.92 \\
-22.52 \pm 1.06 \\
-28.08 \pm 1.20 \\
-33.63 \pm 1.34 \\
21.90-5.55_{3} n \pm \\
(0.14 n-0.06)\end{array}$ & $\begin{array}{r}-7.53 \pm 0.98 \\
-11.56 \pm 1.17 \\
-15.59 \pm 1.36 \\
-19.63 \pm 1.55 \\
20.71-4.03_{3} n \pm \\
(0.19 n-0.35)\end{array}$ & $\begin{array}{r}-18.51 \pm 0.92 \\
-24.28 \pm 1.06 \\
-30.06 \pm 1.20 \\
-35.83 \pm 1.34 \\
21.90-5.773 n \pm \\
(0.14 n-0.06)\end{array}$ & $\begin{array}{r}-9.95 \pm 0.98 \\
-14.33 \pm 1.17 \\
-18.71 \pm 1.36 \\
-23.09 \pm 1.55 \\
20.71-4.37 \circ n \pm \\
(0.19 n-0.35)\end{array}$ \\
\hline
\end{tabular}
where $\Delta$ has the same values as above.

TABLE 2.-Heats of formation of the gaseous normal olefin (alkene-1) hydrocarbons, from solid carbon and gaseous hydrogen at $25^{\circ} \mathrm{C}$ and $0^{\circ} \mathrm{K}$

Nот E.-The estimated uncertainties given here represent the absolute error in each of the values. The uncertainty in the difference between any two values in a given column is about $\pm 0.14 \Delta n$ at $25^{\circ} \mathrm{C}$ and $\pm 0.19 \Delta n$ at $0^{\circ} \mathrm{K}$. 
In order to calculate the corresponding heats of formation at $0^{\circ}$ $\mathrm{K}$, it is necessary to know the value of $H_{298.16}^{\circ}-H_{0}^{\circ}$ for the hydrocarbon, hydrogen, diamond, and graphite. Values for the latter three substances as given in the previous publication [1] are, respectively, $2.023 \pm 0.001,0.125 \pm 0.013$, and $0.251 \pm 0.006$ kilocalories per mole. For ethylene, the values may be taken from the calculations of Smith and Vaughan [19] as $2.534 \pm 0.030$ kilocalories per mole. For the members of the series above ethylene, Kassel $[17,18]$ has estimated that the value is 0.254 kilocalories per mole less than that of the corresponding paraffin. By combining this with the equation previously given by Kassel for the normal paraffin hydrocarbons [1], there is obtained for the gaseous normal olefin (alkene-1) hydrocarbons,

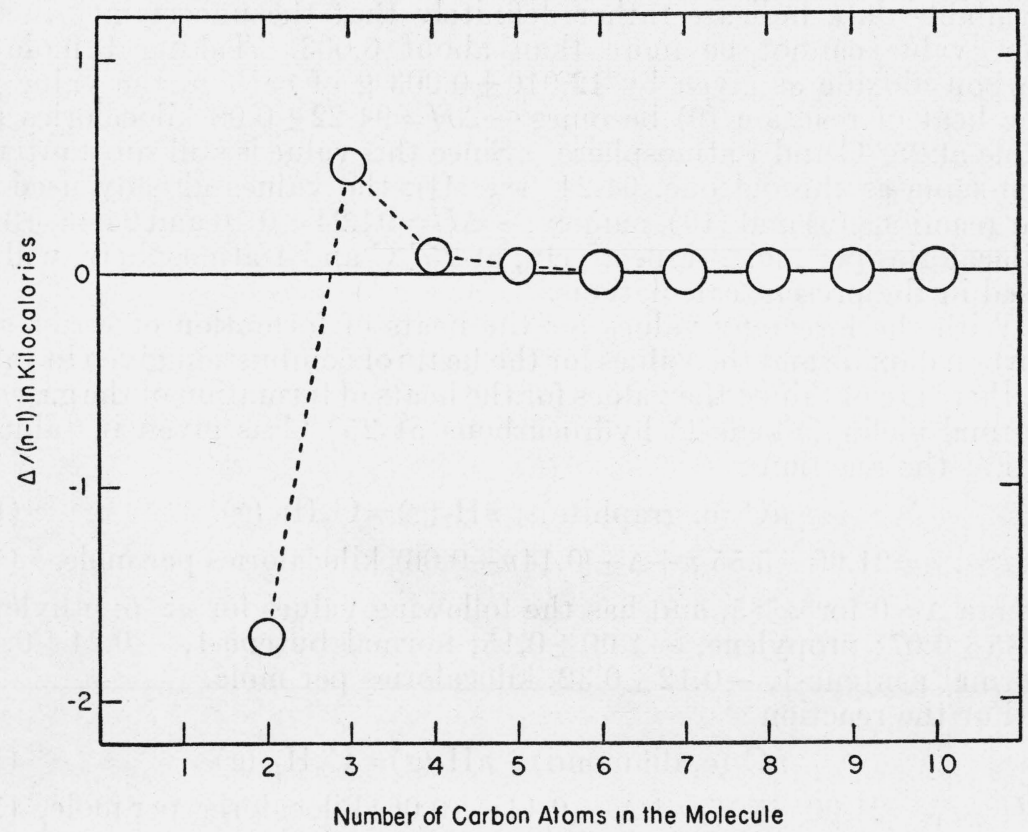

FIGURE 2.-Plot of the deviations from linearity in the relation between the number of carbon atoms in the normal olefin (alkene-1) molecule and its energy of dissociation into normal atoms, at $0^{\circ} \mathrm{K}$.

The scale of ordinates gives the value of $\Delta /(n-1)$, where $\Delta$ is the deviation from linearity in kilocalories per mole and $n$ is the number of carbon atoms in the molecule. The scale of abscissas gives the number of carbon atoms in the molecule.

$\mathrm{C}_{n} \mathrm{H}_{2 n}$, with $n>2, H_{298.16}^{\circ}-H_{0}^{\circ}=1.191+0.754 n(1 \pm 0.01 n)$ kilocalories per mole.

With these values for the increase in heat content of the various molecules in going from $0^{\circ} \mathrm{K}$ to $298.16^{\circ} \mathrm{K}\left(25^{\circ} \mathrm{C}\right)$, there are obtained the values given in table 2 for the heats of formation at $0^{\circ} \mathrm{K}$.

For the reaction

$$
n \mathrm{C}(\mathrm{c}, \text { graphite })+n \mathrm{H}_{2}(\mathrm{~g})=\mathrm{C}_{n} \mathrm{H}_{2 n}(\mathrm{~g})
$$

$\Delta H_{0}^{\circ}=20.71-4.03_{3} n+\Delta \pm(0.19 n-0.35)$ kilocalories per mole,

where $\Delta=0$ for $n>5$, and for $n \leqslant 5$ has the same values as at $25^{\circ} \mathrm{C}$ (equation 1) except for ethylene, for which the value of $\Delta$ is $1.52 \pm 0.08$ kilocalories per mole. 
For the reaction

$$
n \mathrm{C}(\mathrm{c} \text {, diamond })+n \mathrm{H}_{2}(\mathrm{~g})=\mathrm{C}_{n} \mathrm{H}_{2 n}(\mathrm{~g})
$$

$\Delta H_{0}^{\circ}=20.71-4.37_{9} n+\Delta \pm(0.19 n-0.35)$ kilocalories per mole,

where $\triangle$ has the same values as for equation 16 .

In figure 2 is shown the relation between the number of carbon atoms in the molecule and the deviation from linearity in the energy of dissociation [1, 12] of the normal olefin (alkene-1) hydrocarbon into normal gaseous carbon and hydrogen atoms, at $0^{\circ} \mathrm{K}$, according to the reaction

$$
\mathrm{C}_{n} \mathrm{H}_{2 n}(\mathrm{~g})=n \mathrm{C}(\mathrm{g})+2 n \mathrm{H}(\mathrm{g})
$$

The deviation, $\Delta$, is plotted as the function $\Delta /(n-1)$ against $n$, the number of carbon atoms in the molecule. $\Delta$ has the following values at $0^{\circ} \mathrm{K}$ : ethylene, $-1.52 \pm 0.08$; propylene, $1.00 \pm 0.16$; normal butene- $1,0.24 \pm 0.24$; normal pentene- $1,0.12 \pm 0.36 ; n>5,0.00 \pm$ $(0.10 n-0.10)$ kilocalories per mole. It is to be noted that the deviations from linearity are all in the direction of greater energy of dissociation of the molecule, except for ethylene, which is in the direction of lesser energy of dissociation.

\section{REFERENCES}

[1] F. D. Rossini. J. Research NBS 13, 21 (1934). RP692.

[2] F. D. Rossini and J. W. Knowlton. J. Research NBS 19, 249 (1937). RP 1024.

[3] G. B. Kistiakowsky, H. Romeyn, Jr., J. R. Ruhoff, H. A. Smith, and W. E. Vaughan. J. Am. Chem. Soc. 5\%, 65 (1935).

[4] G. B. Kistiakowsky, J. R. Ruhoff, H. A. Smith, and W. E. Vaughan. J. Am. Chem. Soc. 57, 876 (1935); 58, 137 (1936).

[5] F. D. Rossini. BSJ. Research 6, 1 (1931) RP259; 7, 329 (1931) RP343.

[6] F. D. Rossini. Chem. Rev. 18, 233 (1936).

[7] F. D. Rossini. J. Research NBS 17, 629 (1936) RP933.

[8] F. D. Rossini. BSJ. Research 12, 735 (1934) RP686.

[9] P. A. Favre and J. T. Silbermann. Ann. chim. phys. [3] 34, 357 (1852).

[10] P. Zubow. J. Russ. Phys.-Chem. Soc. 30, 926 (1898).

[11] W. Swietoslawski. J. Am. Chem. Soc. 42, 1092 (1920).

[12] F. D. Rossini. J. Research NBS 13, 189 (1934). RP701.

[13] N. S. Osborne, H. F. Stimson, and E. F. Fiock. BSJ. Research 5, 411 (1930) RP209.

[14] N. S. Osborne, H. F. Stimson, and D. C. Ginnings. Mechanical Eng. 57, 162 (1935).

[15] E. F. Fiock. BSJ. Research 5, 481 (1930) RP210.

[16] G. P. Baxter, O. Hönigschmid, and P. LeBeau. J. Am. Chem. Soc. 59, 219 (1937).

[17] L. S. Kassel. J. Chem. Physics 4, 435 (1936).

[18] L. S. Kassel. Private communication.

[19] H. A. Smith and W. E. Vaughan. J. Chem. Physics 3, 341 (1935).

Washington, July 5, 1937. 